\title{
Effect of nicotine on gastric mucosal blood flow and acid secretion
}

\author{
A SONNENBERG and NICOLA HÜSMERT
}

From the Medical Department D, University of Düsseldorf, Düsseldorf, Federal Republic of Germany

SUMmaRY The effects of an intravenous infusion of nicotine at a dose of $2 \cdot 5,5 \cdot 0,7 \cdot 5$, or $10 \cdot 0 \mu \mathrm{g}$ $\mathrm{kg}^{-1} \mathrm{~h}^{-1}$ on pentagastrin-stimulated gastric mucosal blood flow and acid secretion were investigated in eight healthy male non-smokers. Each dose was tested in two males. Gastric neutral red clearance served as a measure of mucosal blood flow. Nicotine reduced volume secretion, acid secretion, and neutral red clearance in a dose dependent manner. In five healthy male smokers smoking of five cigarettes per two hours induced similar changes to the intravenous infusion of $5 \mu \mathrm{g} \mathrm{kg}^{-1} \mathrm{~h}^{-1}$ nicotine. As volume secretion was inhibited more than neutral red clearance, it is concluded that nicotine increases blood supply to the gastric mucosa relatively to the reduced gastric secretion. Nicotine is either not associated with the development of peptic ulcers, or it exerts its ulcerogenic action via other mechanisms than change of acid secretion and gastric mucosal blood flow.

Gastric and duodenal ulcers occur more frequently in smokers than in non-smokers. ${ }^{12}$ Peptic ulcers heal less well in smokers than in non-smokers. ${ }^{3-6}$ Since the work of Virchow, decreased mucosal blood flow has been thought to be one of the factors responsible for the loss of mucosal integrity in the upper gastrointestinal tract. ${ }^{78}$ In the following study the effects of intravenous nicotine infusion on gastric mucosal blood flow and acid secretion were investigated.

\section{Methods}

Thirteen healthy male volunteers with a mean age of 23 years \pm 3 SD were examined. Five volunteers were smokers and eight were non-smokers. None of them had a history of peptic ulcers or described symptoms suggesting a disease of the upper gastrointestinal tract. All subjects gave informed consent. The study had been approved by the local ethical committee.

After an overnight fast the experiments started at $8 \mathrm{am}$. A nasogastric tube was positioned under fluoroscopic control with its tip in the antrum. Gastric contents were continuously aspirated by hand with a $100 \mathrm{ml}$ syringe and pooled in 15 minute fractions. The experiment lasted four hours. During

Received for publication 9 November 1981 the first two hours gastric secretion was stimulated by $0.67 \mu \mathrm{g} \mathrm{kg}^{-1} \mathrm{~h}^{-1}$ pentagastrin given intravenously; during the third and fourth hour $0.67 \mu \mathrm{g} \mathrm{kg}^{-1} \mathrm{~h}^{-1}$ pentagastrin was infused together with $2 \cdot 5,5 \cdot 0,7 \cdot 5$, or $10.0 \mu \mathrm{g} \mathrm{kg}^{-1} \mathrm{~h}^{-1}$ nicotine; each dose was tested in two non-smokers. In the four subjects with 2.5 and $5.0 \mu \mathrm{g} \mathrm{kg}^{-1} \mathrm{~h}^{-1}$ nicotine the experiment was repeated with pentagastrin given alone for four hours. In five smokers nicotine was administered during the third and fourth hour by smoking five cigarettes. One cigarette contained $0.4 \mathrm{mg}$ nicotine and $10 \mathrm{mg}$ tar.

Gastric mucosal blood flow was measured by gastric neutral red clearance: ${ }^{9}$ At the beginning of the experiment the subjects received an intravenous bolus of $250 \mu \mathrm{g} \mathrm{kg}^{-1}$ neutral red, and a continuous intravenous infusion of $250 \mu \mathrm{g} \mathrm{kg}^{-1} \mathrm{~h}^{1}$ neutral red was started. Blood samples of $10 \mathrm{ml}$ were taken from a peripheral arm vein (1) before the bolus injection of neutral red (=blank), (2) every 15 minutes during the first experimental hour, and (3) every 45 minutes during the rest of the experiment. Neutral red was extracted by diethylether from $3 \mathrm{ml}$ samples of the gastric aspirates and from $10 \mathrm{ml}$ samples of blood according to the method of Knight et al. ${ }^{910}$ Neutral red clearance per minute (CL) was calculated as

$$
\mathrm{CL}=\frac{\operatorname{conc}_{\mathrm{G}}}{\operatorname{conc}_{\mathrm{B}}} \times \frac{\mathrm{V}}{15 \mathrm{~min}}
$$


where conc $_{G}$ and $\operatorname{conc}_{B}$ are the concentration of neutral red in the gastric aspirates and in the blood samples, and $\mathrm{V}$ is the gastric content aspirated per 15 minutes. The R-value corresponds to the ratio of neutral red clearance and gastric volume secretion. ${ }^{11}$

Acid concentration was measured by titrating 0.5 $\mathrm{ml}$ of the gastric aspirates with $0 \cdot 1 \mathrm{n} \mathrm{NaOH}$ to a $\mathrm{pH}$ of 7.0 on an automatic burette.

The average value of the four 15 -minute periods during the second hour was regarded as the steady state value of volume secretion, acid secretion, neutral red clearance, and R-value under pentagastrin.

\section{Results}

Neutral red appeared in the gastric juice three to six minutes after the bolus injection. Neutral red clearance and R-value declined for 45 minutes before a steady state was reached. Acid secretion increased during the first 30-45 minutes and remained virtually constant thereafter. Under steady state volume secretion was $80 \pm 15 \mathrm{ml} 15$ $\min ^{-1}(\overline{\mathrm{x}} \pm \mathrm{SD})$, acid secretion $7.5 \pm 1.6 \mathrm{mmol} 15$ $\min ^{-1}$, neutral red clearance $74 \pm 23 \mathrm{ml} \mathrm{min}^{-1}$, and the $\mathrm{R}$-value $14 \pm 5$. In the four subjects in whom pentagastrin infusion without nicotine lasted four instead of two hours mean acid secretion and neutral red clearance in the fourth hour were $96 \pm 2 \%$ and $95 \pm 3 \%$ of the mean values during the second hour.

With a dose of $5-10 \mu \mathrm{g} \mathrm{kg}^{-1} \mathrm{~h}^{-1}$ the effect of nicotine started 30-45 minutes after the beginning of the intravenous infusion, with $2.5 \mu \mathrm{g} \mathrm{kg} \mathrm{kg}^{-1}$ nicotine the effect started after 60 minutes of

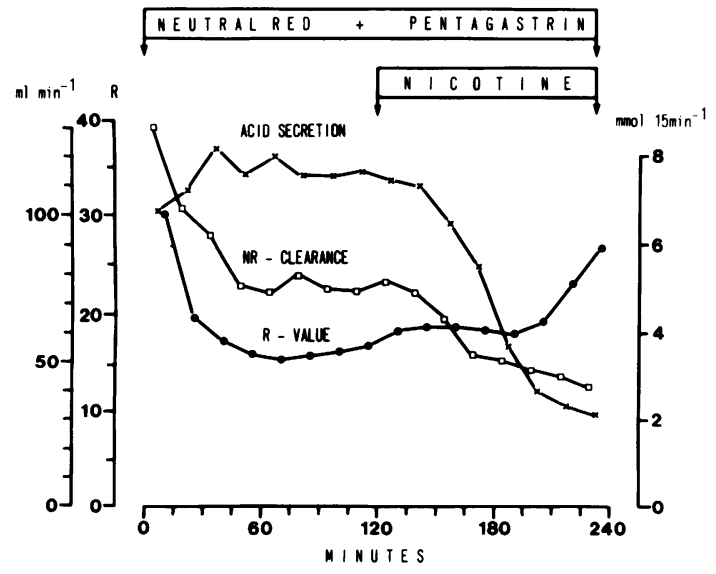

Fig. 1 Effects of $5 \mu \mathrm{kg}^{-1} \mathrm{~h}^{-1}$ nicotine in one experiment. nicotine infusion. Figure 1 shows a typical experiment with $5 \mu \mathrm{g} \mathrm{kg}^{-1} \mathrm{~h}^{-1}$ nicotine. In all subjects nicotine induced a decrease of volume secretion, acid secretion, and neutral red clearance. As volume and acid secretion were inhibited more than the neutral red clearance, the $\mathrm{R}$-value increased. The effects of nicotine were dose dependent (Fig. 2). Nicotine at a dose of $7.5 \mu \mathrm{g} \mathrm{kg}^{-1} \mathrm{~h}^{-1}$ was nearly as potent as at a dose of $10 \cdot 0 \mu \mathrm{g} \mathrm{kg}^{-1} \mathrm{~h}^{-1}$.

Smoking five cigarettes elicited an effect similar to an intravenous dose of $5 \mu \mathrm{g} \mathrm{kg}^{-1} \mathrm{~h}^{-1}$ nicotine: volume secretion fell to $63 \pm 14 \%$, acid output fell to $38 \pm 20 \%$, and neutral red clearance fell to $58 \pm 22 \%$ of pentagastrin level, the R-value increased to $145 \pm 52 \%$ of pentagastrin level, respectively.

\section{Discussion}

In our experiment, nicotine after smoking five cigarettes or given intravenously proved a potent inhibitor of pentagastrin-stimulated gastric secretion and mucosal blood flow estimated by the neutral red clearance of the stomach. Gastric mucosal blood flow was inhibited less than secretion of acid and volume. Thus, the ratio of blood flow and gastric secretion $(=R)$ increased.

The gastric clearance of ${ }^{14} \mathrm{C}$-aminopyrine and neutral red have frequently been used to measure gastric mucosal blood flow in man. ${ }^{12-14}$ The following limitations of the method must be taken

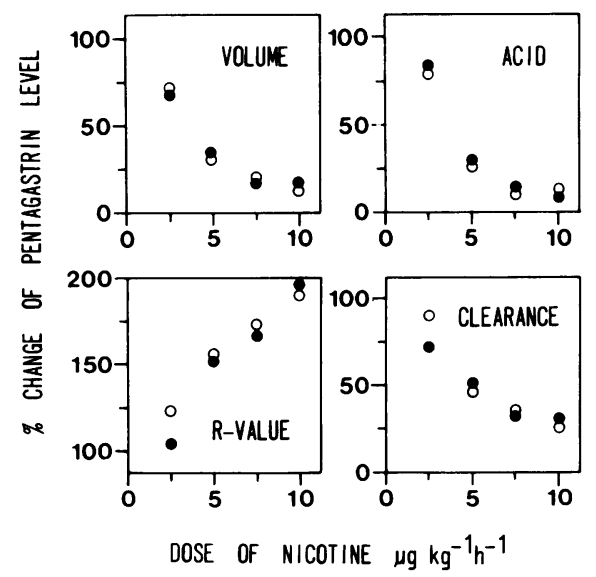

Fig. 2 Dose response of gastric volume secretion, acid output, $R$-value, and neutral red clearance to intravenous infusion of nicotine. One hundred per cent corresponds to

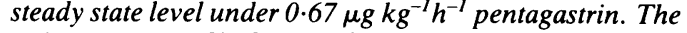
points represent \% change of pentagastrin level by nicotine in the last sampling period of the fourth hour. 
into account: ${ }^{15} 16$ neutral red, like aminopyrine, initially accumulates in the parietal cells and is consecutively washed out into the gastric lumen by the acid secretion. This explains the initial decline of the neutral red concentration in the gastric juice and the corresponding behaviour of the clearance and the R-value (Fig. 1). Under steady state conditions neutral red clearance is only a relative measure of gastric mucosal blood flow. It also depends on the secreting state of the mucosa.

Most of life is spent in the basal rather than in the stimulated state of the stomach. For methodological reasons, however, the effects of nicotine were studied in the stimulated state: the inhibitory actions of drugs on acid secretion and neutral red clearance being studied more reliably in this condition. Steady state of gastric neutral red clearance is reached earlier and is more stable in the stimulated than in the basal state. No principal difference is known to exist between the parietal cell mechanisms generating acid at low or high rates.

In order to check how much of the acid secretory response to pentagastrin faded after prolonged stimulation, in four subjects pentagastrin infusion was continued for four hours. Acid output during the fourth hour dropped by less than $5 \%$ compared with the second hour. Hence, the changes observed with nicotine are due to the drug itself and not to a reduced response to pentagastrin. Nicotine markedly reduced pentagastrin-stimulated acid secretion. The $\mathrm{pH}$ value of the gastric juice under nicotine, nevertheless, always stayed well below 2 , and enough volume was secreted for the acid partition hypothesis of neutral red in the gastric lumen to remain valid. ${ }^{17}$ As acid secretion and neutral red clearance declined simultaneously, it is not possible to decide whether the fall in neutral red clearance is secondary to an inhibition of acid secretion. On the basis of the results presented, however, it seems unlikely that nicotine exerts any ulcerogenic action via a reduction of mucosal blood flow, because it increases the ratio of blood flow to gastric secretion. This may mean that nicotine even ameliorates blood supply to the gastric mucosa relatively to the reduced acid secretion.

Two possible explanations arise from our results for the association between smoking and ulcer disease: ${ }^{1-4}$ either nicotine is irrelevant for the development of peptic ulcer, or mechanisms other than altered blood flow and acid secretion are responsible for an ulcerogenic action of nicotine. For instance, nicotine reduces the pancreatic bicarbonate secretion. ${ }^{18}$ It thus may favour the development of duodenal ulcer. In relation to or independently of its inhibitory action on acid secretion nicotine may also reduce the supply of bicarbonate to the gastric mucosa; bicarbonate has been shown to be necessary for the prevention of peptic ulcers. ${ }^{19}$

This study was supported by a grant of the Minister für Wissenschaft und Forschung des Landes Nordrhein-Westfalen.

\section{References}

1 Harrison AR, Elashoff JD, Grossman MI. Cigarette smoking and ulcer disease. In: Smoking and health. $A$ report of the surgeon general. DHEW publication no. 79-50066. 1979: 9.3-9.21.

2 Bennett JR. Smoking and the gastrointestinal tract. Gut 1972; 13: 658-65.

3 Doll R, Jones FA, Pygott F. Effect of smoking on the production and maintenance of gastric and duodenal ulcers. Lancet 1958; I: 657-62.

4 Peterson WL, Sturdevant RAL, Frankl HD et al. Healing of duodenal ulcer with an antacid regimen. $N$ Engl J Med 1977; 297: 341-5.

5 Korman MG, Shaw RG, Hansky J, Schmidt GT, Stern AI. Influence of smoking on healing rate of duodenal ulcer in response to cimetidine or high-dose antacid. Gastroenterology 1981; 80: 1451-3.

6 Sonnenberg A, Müller-Lissner SA, Vogel E et al. Predictors of duodenal ulcer healing and relapse. Gastroenterology 1981; 81: 1061-7.

7 Virchow R. Historisches, Kritisches und Positives zur Lehre der Unterleibsaffektionen. Arch Pathol Anatom 1853; 5: 281-387.

8 Jacobson ED. The circulation of the stomach. Gastroenterology 1965; 45: 85-109.

9 Knight SE, McIsaak RL, Rennie CD et al. Studies of gastric mucosal blood flow: neutral red clearance and dose response curve analysis. In: Fielding LP, ed. Gastro-intestinal mucosal blood flow. Edinburgh: Churchill Livingstone, 1980: 105-24.

10 Knight SE, McIsaak RL. Neutral red clearance as an estimate of gastric mucosal blood flow in dogs. $J$ Physiol (Lond) 1977; 267: 45-6P.

11 Jacobson ED, Linford RH, Grossman MI. Gastric secretion in relation to mucosal blood flow studied by a clearance technique. J Clin Invest 1966; 45: 1-13.

12 Guth PH, Baumann H, Grossman MI, Aures D, Elashoff J. Measurement of gastric mucosal blood flow in man. Gastroenterology 1978; 74: 831-4.

13 Knight SE, McIsaak RL, Fielding LP. The effect of highly selective vagotomy on the relationship between gastric mucosal blood flow and acid secretion in man. Br J Surg 1978; 65: 721-3.

14 Knight SE, McIsaak RL, Rennie CD. The effect of histamine and histamine antagonists on gastric acid secretion and mucosal blood flow in man. Br J Surg 1980; 67: 266-8. 
15 Sonnenberg A, Blum AL. Limitations to measurement of gastric mucosal blood flow by ${ }^{14} \mathrm{C}$-aminopyrine clearance. In: Fielding LP, ed. Gastro-intestinal mucosal blood flow. Edinburgh: Churchill Livingstone, 1980: 43-58.

16 Müller-Lissner SA, Sonnenberg A, Blum AL. Does gastric aminopyrine clearance reflect gastric mucosal blood flow or parietal cell function? Gut 1981; 22: 997-1002.

17 Shore PA, Brodie BB, Hogben CAM. The gastric secretion of drugs: A $\mathrm{pH}$ partition hypothesis. $J$ Pharmacol Exp Ther 1957; 119: 361-9.

18 Konturek SJ, Dale J, Jacobson ED, Johnson LR. Mechanisms of nicotine-induced inhibition of pancreatic secretion of bicarbonate in the dog. Gastroenterology 1972; 62: 425-9.

19 Barzilai A, Schiessel R, Kivlaakso E et al. Effect of 16-16-dimethyl-prostaglandin $E_{2}$ on ulceration of isolated amphibian gastric mucosa. Gastroenterology 1980; 78: $1508-12$. 